\title{
JAK2 NP_004963.1:p.Y931C
}

National Cancer Institute

\section{Source}

National Cancer Institute. AAK2 NP 004963.1:p.Y931C. NCI Thesaurus. Code C105912.

A change in the amino acid residue at position 931 in the tyrosine-protein kinase JAK2

protein where tyrosine has been replaced by cysteine. 